[CONTRIBUTtON FROM THE COBB ChEMICAL LABORATORY OF THE UNIVERSITY OF VIRGINIA]

\title{
THE EQUILIBRIUM OF THE REACTION BETWEEN METALLIC SILVER, CUPRIC CHLORIDE IN AQUEOUS SOLUTION, AND SOLID CUPROUS AND SILVER CHLORIDES
}

\author{
By Graham Edgar and Lawrence S. Cannon \\ Received August 28, 1922
}

\section{Introduction}

The greater number of calculations of specific electrode potential and of free energy, of reactions between ionized substances, have been made from measurements of electromotive force, rather than from equilibrium data, partially because of the precision with which such measurements may be made, and partially because of the experimental difficulties apt to attend the measurement of the equilibrium concentrations. However, although the electrical measurements may be extremely precise and reproducible, the calculations based upon them frequently involve somewhat uncertain assumptions regarding the activities of the ions, liquid potential, and other factors. It seems desirable, therefore, to measure also characteristic equilibria in reactions between electrolytes in such cases as may be experimentally possible, in order to compare the results with those obtained by electrical measurements, and to add to our knowledge of the activities of ionized substances.

The reaction

$$
\underline{\mathrm{CuCl}}+\underline{\mathrm{AgCl}}+\mathrm{Aq}=\mathrm{Cu}^{++} \mathrm{Cl}_{2}^{-} \mathrm{Aq}+\underline{\mathrm{Ag}}
$$

proceeds fairly rapidly at ordinary temperatures to a definite condition of equilibrium, and seems particularly suitable for study. The present investigation includes the experimental measurement of this equilibrium, and the calculation of the energy changes involved.

\section{Experimental}

Preparation of Materials.-CUPROUS CHLORIDE was prepared by dissolving a high quality imported product in conc. hydrochloric acid, diluting with water, filtering, washing the precipitated cuprous chloride with dil. hydrochloric acid, and finally with alcohol and ether. It was then dried in a desiccator in a current of carbon dioxide. The product was pure white and crystalline.

CUPRIC CHLORIDE was prepared by recrystallizing a high quality imported material.

SILVER CHLORIDE was prepared by adding hydrochloric acid to a dilute solution of c. P. silver nitrate, filtering on asbestos, and washing thoroughly with water. The precipitate was then dried at $100^{\circ}$. All operations were carried out in a room into which only red light was admitted, and the product was preserved in amber bottles. It was always pure white in color.

SIIVER was prepared by electrolyzing a solution of silver nitrate, using as anode a platinum disk surrounded by a porous cup, and as cathode a platinum wire just dipping into the solution. By using a fairly heavy current and agitating the cathode from time to time, the silver breaks away from the cathode almost as soon as formed and falls to 
the bottom of the cathode chamber. It was filtered, washed thoroughly with hot water, and dried at $100^{\circ}$. It consisted of very small but distinet crystals.

Other reagents used were good grade commercial products. Solutions employed for titration were carefully standardized before each set of measurements. Calibrated volumetric apparatus was employed, and all precautions of analysis were observed.

Experimental Technique.-Bottles of dark amber glass, of about $100 \mathrm{cc}$. capacity, were used to contain the reaction mixtures. These bottles were nearly filled with either cupric chloride solution, containing a definite amount of hydrochloric acid (see the discussion below), or dil. hydrochloric acid alone, according to the side from which the equilibrium was to be approached. Carbon dioxide was then bubbled through the solution to remove dissolved oxygen. While the carbon dioxide was passing through the solution the reacting solids were added, silver alone being added to the cupric chloride solutions, and silver chloride, cuprous chloride, and silver being added to the hydrochloric acid. The passage of carbon dioxide was continued for a time, and then the bottles were stoppered, sealed with paraffin, and placed in a thermostat, where they were rotated for 3 to 6 weeks. The temperature was kept at $25^{\circ}$ or $40^{\circ}\left( \pm 0.02^{\circ}\right)$.

Methods of Analysis.-After reaching equilibrium the solutions were analyzed for cupric copper, cuprous copper and total chlorine, by a method which proved entirely satisfactory.

Cupric copper was determined by running a portion of the equilibrium solution into a solution containing $2 \mathrm{~g}$. of potassium iodide and $2 \mathrm{cc}$. of conc. acetic acid. After the solution had been stirred for a minute or so the liberated iodine was titrated with dil. sodium thiosulfate solution, using starch as indicator.

Cuprous copper was determined by running a second portion of the equilibrium solution into a dilute solution of ferric sulfate acidified with sulfuric acid. The mixture was then titrated with dil. potassium permanganate solution. The cuprous salt reduces the ferric salt, and thus avoids atmospheric oxidation during the titration. The color of the cupric salt was never sufficient to mask the end-point, nor was the concentration of chloride sufficient to cause error.

Total chlorine was determined by adding to the solution in which cuprous copper had been determined, an excess of standard silver nitrate. The mixture was heated, the silver chloride filtered off, and the excess of silver determined by titration with ammonium thiocyanate.

Preliminary experiments upon known mixtures demonstrated that the methods were thoroughly reliable.

The concentrations thus determined expressed in moles per $1000 \mathrm{~g}$. of water are given in Cols 2, 3 and 4 of Table 1 . In this table odd-numbered experiments approach the equilibrium from the left of Fquation 1, and even-numbered experiments from the right.

It will be noticed that in addition to the reacting substances, all solutions contained carbon dioxide and some free hydrochloric acid. The former, used to displace the air, can hardly be expected to affect the equilibrium measurably, as it is so little ionized, particularly in the presence of a strong acid. In some preliminary experiments it was not used, and no noticeable differences were observed.

The hydrochloric acid was added to prevent the hydrolysis of the cupric chloride, and particularly that of the cuprous chloride into cuprous hydroxide and free acid. ${ }^{1}$

Its presence also lessens the possibility of formation of metallic copper, by the reaction:

$$
2 \underline{\mathrm{CuCl}}=\underline{\mathrm{Cu}}+\mathrm{CuCl}
$$

although this reaction would probably not occur under the conditions here employed. The concentration of hydrochloric acid was varied from nearly zero to approximately $0.25 \mathrm{M}$.

1 Bodländer and Storbeck, Z, anorg. Chem., 31, 1, 458 (1902). 


\section{Treatment of Data}

Examination of the experimental data shows at once that a definite equilibrium exists in the reacting system, as the concentrations resulting from approaching the equilibrium from opposite sides are practically identical.

It is also obvious that the equilibrium concentrations vary markedly with the hydrochloric acid added.

Since the silver, silver chloride, and cuprous chloride are all solids, their activities are presumably constant, and the only substance whose activity may vary is the cupric chloride (more strictly, its ions).

If we write the mass-law expression

$$
K=a \mathrm{Cu}^{++} \times a^{2} \mathrm{Cl}^{-}
$$

we need only to evaluate the activities of the cupric and chloride ions in order to calculate the constant. Since the activity ${ }^{2}$ of each ion is the product of its molality by its activity coefficient, we may write

$$
K=\gamma \mathrm{Cu}^{++} \times M_{\mathrm{Cu}++} \times\left(\gamma \mathrm{Cl} \times M_{\mathrm{Cl}^{-}}\right)^{2}
$$

where $\gamma$ represents the activity coefficient, and $M$ the total or stoichiometrical molality ${ }^{2,3}$ of the ion in question. (It should be noted that the molality thus defined includes undissociated salt, or intermediate ions, but does not include complexes which may perhaps be formed in the solution.)

The first calculation is that of the molality of the different ion species in the equilibrium mixture.

It has been shown by Bodländer and Storbeck ${ }^{1}$ and by Noyes and Chow, ${ }^{4}$ that for moderate concentrations of chloride-ion, practically all cuprous copper is contained in solution as the complex ion, $\mathrm{CuCl}_{2}-$, although in very dilute chloride solutions there are small amounts of cuprous ion, and in concentrated chloride solutions there may be some $\mathrm{CuCl}_{3}{ }^{--}$. As a first approximation we may assume all of the cuprous copper as $\mathrm{CuCl}_{2}{ }^{-}$, and the molality of this ion is given directly by Col. 2 , Table I.

The cupric ion may presumably be considered not to form complexes (see further below) and its molality is therefore given directly by Col. 1 , Table I.

The molality of the chloride ion is then found by subtracting twice the molality of the cuprous copper (Col. 1) from the total chloride (Col. 3).

The molality of the hydrogen ion is given (assuming $\mathrm{HCl}$ and $\mathrm{HCuCl}_{2}$ ) by subtracting from the total chloride twice the molality of the cupric copper plus the molality of the cuprous copper.

It may be noted that Noyes and Chow, ${ }^{4}$ in agreement with Bodländer

2 Throughout this paper the terms employed are essentially those used by Lewis and Randall, This JovrnaL, 43, 1112 (1921).

${ }^{3}$ Brönsted, ibid., 42, 761 (1920).

${ }^{4}$ Noyes and Chow, ibid., 40, 739 (1918). 
TABLE I

COMPOSITION OF EQUILIBRIUM SOLUTIONS

\begin{tabular}{|c|c|c|c|c|c|}
\hline $\begin{array}{c}\text { Cupric } \\
\text { copper } \\
\text { molality } \\
\times 10^{3} \\
\text { (a) }\end{array}$ & $\begin{array}{l}\text { Cuprous } \\
\text { copper } \\
\text { molality } \\
\times 10^{3} \\
\text { (b) }\end{array}$ & $\begin{array}{c}\text { Total } \\
\text { chloride } \\
\text { molality } \\
\times 10^{3} \\
\text { (c) }\end{array}$ & $\begin{array}{l}\text { Chloride-ion } \\
\text { molality } \\
\times 10^{3}\end{array}$ & $\begin{array}{l}\text { Hydrogen-ion } \\
\text { molality } \\
\times 10^{3}\end{array}$ & $\frac{b}{c-2 b}$ \\
\hline \multicolumn{6}{|c|}{ Aт $25^{\circ}$} \\
\hline 9.76 & 1.75 & 27.2 & 23.7 & 5.93 & 0.0738 \\
\hline 9.76 & 1.75 & 27.2 & 23.7 & 5.93 & 0.0738 \\
\hline 8.13 & 1.85 & 30.4 & 26.7 & 8.67 & 0.0693 \\
\hline 8.13 & 1.80 & 30.4 & 26.7 & 8.67 & 0.0693 \\
\hline 4.11 & 2.65 & $4 \tilde{5} .2$ & 39.9 & 29.13 & 0.0664 \\
\hline 4.11 & 2.65 & 45.2 & 39.9 & 29.13 & 0.0664 \\
\hline 1.34 & 5.55 & 95.2 & 84.1 & 70.36 & 0.0660 \\
\hline 1.34 & 5.60 & 95.2 & 84.0 & 70.26 & 0.0667 \\
\hline 0.57 & 11.45 & 197.2 & 174.3 & 161.7 & 0.0657 \\
\hline 0.57 & 11.45 & 197.2 & 174.3 & 161.7 & 0.0657 \\
\hline 0.48 & 15.00 & 252.0 & 222.0 & 206.0 & 0.0674 \\
\hline 0.48 & 15.05 & 252.8 & 222.7 & 206.7 & 0.0676 \\
\hline 0.38 & 17.92 & 309.2 & 273.4 & 254.7 & 0.0656 \\
\hline 0.38 & 18.05 & 309.3 & 273.2 & 254.5 & 0.0661 \\
\hline \multicolumn{6}{|c|}{ Ат $40^{\circ}$} \\
\hline 10.42 & 2.95 & 26.4 & 20.5 & 2.71 & 0.1439 \\
\hline 10.42 & 2.95 & 26.4 & 20.5 & 2.71 & 0.1439 \\
\hline 8.14 & 3.20 & 29.4 & 23.0 & 3.60 & 0.1392 \\
\hline 8.14 & 3.08 & 29.6 & 23.44 & 4.16 & 0.1315 \\
\hline 5.71 & 3.90 & 37.4 & 30.6 & 15.28 & 0.1275 \\
\hline 5.71 & 3.90 & 37.4 & 30.6 & 15.28 & 0.1275 \\
\hline 3.20 & 5.00 & 51.8 & 41.8 & 30.40 & 0.1196 \\
\hline 3.14 & 4.98 & 52.4 & 42.44 & 31.18 & 0.1173 \\
\hline 2.00 & 6.60 & 70.8 & 57.6 & 47.0 & 0.1146 \\
\hline 2.00 & 6.62 & 70.8 & 57.56 & 46.94 & 0.1150 \\
\hline 1.24 & 8.90 & 100.4 & 82.6 & 71.22 & 0.1078 \\
\hline 1.24 & 8.90 & 100.4 & 82.6 & 71.22 & 0.1078 \\
\hline 1.00 & 10.94 & 120.6 & 98.7 & 85.76 & 0.1108 \\
\hline 1.00 & 10.93 & 120.6 & 98.7 & 85.77 & 0.1107 \\
\hline 0.832 & 17.00 & 200.5 & 166.5 & 181.8 & 0.1021 \\
\hline 0.832 & 17.50 & 203.0 & 1680 & 183.8 & 0.1042 \\
\hline
\end{tabular}

and Storbeck ${ }^{1}$ found that for solutions between $0.05 \mathrm{M}$ and $0.25 \mathrm{M}$ in chloride ion, we have

$$
\frac{\text { Tatal cuprous copper }}{\text { Total chloride }-2 \text { total cuprous copper }}=K
$$

while at very low chloride-ion concentrations this ratio increases, indicating the presence of appreciable cuprous ion. This is borne out by the present data (Col. 6, Table I) in which at $25^{\circ}$ the ratio is about 0.0667 in all except the two most dilute solutions, and at $40^{\circ}$ the ratio is about 0.109 except in the more dilute solutions. (Noyes and Chow found 0.0661 and 0.111 for these values.) If we accept the increase in this ratio as indicating 
formation of cuprous ions we may calculate the cuprous copper present as $\mathrm{CuCl}_{2}-$ from Equation 5 and call the remainder cuprous ion. This alters only slightly the molality of the chloride ion.

In Table II are given the molalities of the different ion species calculated on this assumption, taking the average values from the duplicate experiments of Table I.

\begin{tabular}{|c|c|c|c|c|c|c|c|}
\hline \multicolumn{8}{|c|}{ TABLE II } \\
\hline $\begin{array}{l}\text { Cupric- } \\
\text { ion } \\
\text { molality } \\
\times 10^{3}\end{array}$ & $\begin{array}{l}\mathrm{CuCl}_{2}^{-} \\
\text {molality } \\
\times 10^{3}\end{array}$ & $\begin{array}{l}\text { Chloride- } \\
\text { ion } \\
\text { molality } \\
\times 10^{3}\end{array}$ & $\begin{array}{l}\text { Cuprous- } \\
\text { ion } \\
\text { molality } \\
\times 10^{3}\end{array}$ & $\begin{array}{l}\text { Ionic } \\
\text { strength }\end{array}$ & $\begin{array}{c}\text { Activity } \\
\text { coefficient } \\
\mathrm{Cl}^{-}\end{array}$ & $\begin{array}{c}\text { Activity } \\
\text { coefficient } \\
\mathrm{Cu}^{++}\end{array}$ & $\begin{array}{c}\text { Equilibrium } \\
\text { constant } \\
K \times 10^{6}\end{array}$ \\
\hline \multicolumn{8}{|c|}{ AT $25^{\circ}$} \\
\hline 9.76 & 1.60 & 24.02 & 0.15 & 0.0354 & 0.861 & 0.437 & 1.824 \\
\hline 8.13 & 1.78 & 26.94 & 0.07 & 0.0368 & 0.860 & 0.431 & 1.876 \\
\hline 4.11 & 2.65 & 39.9 & . & 0.0466 & 0.845 & 0.400 & 1.869 \\
\hline 1.34 & 5.58 & 84.05 & . & 0.0910 & 0.800 & 0.327 & $(1.981)$ \\
\hline 0.57 & 11.45 & 174.3 & 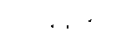 & 0.1863 & 0.750 & 0.260 & $(2.560)$ \\
\hline 0.48 & 15.03 & 222.4 & . & 0.2375 & 0.738 & 0.24 & $(3.10)$ \\
\hline 0.38 & 18.00 & 273.3 & . & 0.2920 & 0.725 & 0.22 & $(3.27)$ \\
\hline \multicolumn{8}{|c|}{ Aт $40^{\circ}$} \\
\hline 10.42 & 2.36 & 21.68 & 0.59 & 0.0345 & 0.863 & 0.439 & 1.601 \\
\hline 8.14 & 2.64 & 24.22 & 0.50 & 0.0350 & 0.862 & 0.436 & 1.547 \\
\hline 5.71 & 3.34 & 30.71 & 0.56 & 0.0398 & 0.854 & 0.422 & 1.657 \\
\hline 3.17 & 4.66 & 42.77 & 0.34 & 0.0506 & 0.839 & 0.388 & 1.584 \\
\hline 2.00 & 6.34 & 58.13 & 0.27 & 0.0665 & 0.821 & 0.355 & 1.617 \\
\hline 1.24 & 8.90 & 82.6 & . & 0.0927 & 0.799 & 0.327 & 1.649 \\
\hline 1.00 & 10.93 & 98.7 & & 0.1106 & 0.787 & 0.312 & $(1.883)$ \\
\hline 0.832 & 17.3 & 167.5 & & 0.18 .52 & 0.751 & 0.26 & $(3.42)$ \\
\hline
\end{tabular}

Accepting the molalities given in Table II as representing the most probable values, we have next to determine the activity coefficients of the cupric and chloride ion.

Although Brönsted ${ }^{5}$ has given some objection to the suggestions of MacInnes $^{6}$ and Harned ${ }^{7}$ that the activity coefficients of each ion may be different and independent, the extensive calculations of Lewis and Randal1 ${ }^{2}$ based upon this assumption seem to substantiate the theory, and furnish the most satisfactory method at present available of evaluating ionic activities in mixed electrolytes. According to Lewis and Randall the activity coefficient of any given electrolyte is identical at identical values of the "ionic strength," a function readily calculable in our case from the molalities of the ionic species present in solution by the relation

$$
\mu=\frac{4 M_{\mathrm{Cu}^{+}+}+M_{\mathrm{Cl}^{-}}+2 M_{\mathrm{CuCl}^{-}}+M_{\mathrm{Cu}^{+}}+M_{\mathrm{HCl}}}{2}
$$

The ionic strength of the solutions in question is given in Col. $\tilde{5}$, Table II. Following MacInnes'b assumption that potassium ion and chloride ion

5 Brönsted, This Journal, 44, 877 (1922).

"MacInnes, ibid., 41, 1086 (1919).

7 Harned, ibid., 42, 1818 (1920). 
have identical activity coefficients it becomes possible to calculate the activity coefficients of the cupric and chloride ions from the activity coefficients of any salts yielding these ions, at equivalent ionic strength.

The data for the activity coefficients of chloride ion seem quite satisfactory, and these values, calculated by interpolation of the data of Lewis and Randa11 ${ }^{2}$ (Table XXVI) are given in Col. 6, Table II. Data for the activity coefficients of bivalent ions are much less satisfactory. Lewis and Linhart ${ }^{8}$ calculated the activity coefficients of several metal sulfates including cupric sulfate from freezing-point data, but Lewis and Randall ${ }^{2}$ consider that these values are too low, and give averaged values for the activity coefficients of "MeSO ${ }_{4}$," from which by combination with the values for potassium sulfate, and making Macinnes' assumption of identical activity coefficients for potassium ion and chloride ion, we may calculate the activity coefficients of " $\mathrm{Me}^{++}$" at corresponding values of the ionic strength by the relation

$$
\gamma \mathrm{Me}^{++}=\frac{\gamma^{2} \mathrm{MeSO}_{4} \times \gamma^{2} \mathrm{~K}+}{\gamma^{3} \mathrm{~K}_{2} \mathrm{SO}_{4}}
$$

Values for the activity coefficients thus calculated are given in Col. 7 , 'Table II. They differ only slightly from those calculated by Lewis and Randall (apparently from data for barium chloride).

If we assume the validity of the data of Lewis and Linhart for cupric sulfate, we obtain much lower values for the activity coefficients by the same method of calculation.

If we now calculate the equilibrium constant from Equation 4, using the activity coefficients of Cols. 6 and 7 , and the molalities of Cols. 1 and 3 , Table II, the more dilute solutions show a very good agreement with one another; but as the solutions become more concentrated there is a pronounced "trend" in the values of the constant. It seems probable that fewer disturbing factors enter into the situation in the more dilute solutions, and we may accept the average of their results as $1.86 \times 10^{-6}$, at $25^{\circ}$, and $1.61 \times 10^{-6}$ at $40^{\circ}$, as the most probable values. Possible reasons for the increase in the value of the constant at high concentration of hydrochloric acid are discussed below.

From the two constants the increase in heat content of the system may be calculated from the relation

$$
\Delta H=\frac{R T^{2} \mathrm{~d} \ln K}{\mathrm{~d} T}
$$

From the constants at $25^{\circ}$ and at $40^{\circ}$ we obtain $\Delta H=-1755$ cal.

For the free energy increase of the reaction we obtain at $25^{\circ}$

$$
\Delta F=-R T \ln K=7820 \mathrm{cal} \text {. }
$$

\section{Discussion of Results}

The evident trend in the values of the equilibrium constant may be due to one or both of two causes. The activity coefficients of either ion

${ }^{s}$ Lewis and Linhart, This Journal, 41, 1951 (1919). 
(particularly that of the copper) may decrease more rapidly than the calculations show; or the molality of the cupric ion and to a less extent, of the chloride ion may be affected by partial formation of complexes in the more concentrated solutions. This is known to occur in conc. hydrochloric acid solutions to a considerable extent, and it seems reasonahle to assume that it may occur to an appreciable extent in the solutions here considered, so that the actual molality of the cupric ion may be lower than that assumed. It is well known that mercuric and cadmium halides are very abnormal in this respect, and it may well be that cupric chloride is somewhat so. In any case it seems justifiable to neglect the results obtained in the more concentrated acid solutions.

\section{Comparison with Other Data}

From the data of Noyes and Ellis ${ }^{9}$ we have for the molal electrode potential of the silver chloride electrode, $E_{\mathrm{AgCl}}=-0.2238$ volt, equivalent to a free-energy change of $5164 \mathrm{cal}$.

Lewis and Lacey ${ }^{10}$ measured the specific electrode potential of copper, and obtained the value, $E_{\mathrm{Cu}}=-0.3469$ volt; $\Delta F=16008 \mathrm{cal}$.

Finally, Noyes and $\mathrm{Chow}^{4}$ measured the potential of copper in solutions containing solid cuprous chloride and chloride ion, and obtained for the molal potential, $E_{\mathrm{CuCl}}=-0.1200$ volt; $\Delta F=2769 \mathrm{cal}$.

Combining the equations

$$
\begin{array}{cl}
\underline{\mathrm{Cu}}+2 \oplus=\mathrm{Cu}^{++} & ; \Delta F=16008 \mathrm{cal} . \\
\underline{\mathrm{Cu}}+\mathrm{Cl}^{-}+\oplus=\underline{\mathrm{CuCl}} & ; \Delta F=2768 \mathrm{cal} . \\
\underline{\mathrm{Ag}}+\mathrm{Cl}^{-}+\oplus=\underline{\mathrm{AgCl}} & ; \Delta F=5164 \text { cal. }
\end{array}
$$

we obtain for the reaction

$$
\underline{\mathrm{CuCl}}+\underline{\mathrm{AgCl}}=\mathrm{Cu}^{++}+2 \mathrm{Cl}^{-}+\underline{\mathrm{Ag}} \quad ; \Delta F=8075 \mathrm{cal} .
$$

Considering the uncertainties involved in many of the calculations it must be said that the agreement of this value with that of Equation 8 is very good, and lends support to the general method employed by Lewis and Randall for the calculation of activities of mixed electrolytes. It may be noted that an even closer agreement would be obtained by employing activity coefficients for cupric ion calculated from the freezing-point data of Lewis and Linhart for copper sulfate, but in view of the uncertainty of their data this seems hardly justifiable.

The available data for the heat of reaction are most uncertain. From the data in I,andolt-Börnstein ${ }^{11}$ we may calculate values ranging from -1920 cal. (Berthelot) to +520 cal. (Thomsen), as compared with our value of $+1755 \mathrm{cal}$. In view of the extremely indirect methods by which

\footnotetext{
${ }^{9}$ Noyes and Ellis, This Journal, 39, 2532 (1917).

${ }^{10}$ Lewis and Lacey, ibid., 36, 804 (1914).

11 Landolt-Börnstein, "Tabellen," 4th Ed.
} 
the calorimetric data were obtained it seems probable that our value is nearer the truth.

By combination of Equations 8 and 11 we obtain for the reaction

$$
\mathrm{CuCl}+\mathrm{Cl}^{-}+\oplus=\mathrm{Cu}^{++}+2 \mathrm{Cl}^{-}
$$

$\Delta F=12984$ cal., corresponding to a value of $-0.5627 v$. for the molal electrode potential for this reaction.

\section{Summary}

1. The equilibrium of the reaction

$$
\underline{\mathrm{CuCl}}+\underline{\mathrm{AgCl}}=\mathrm{Cu}^{++} \mathrm{Cl}_{2}-\mathrm{Aq}+\underline{\mathrm{Ag}}
$$

has been measured at $25^{\circ}$ and at $40^{\circ}$ in the presence of varying quantities of hydrochloric acid.

2. The equilibrium constants have been calculated, making use of the principle of "ionic strength."

3. The increases in free energy and heat content of the system have been calculated and compared with the values obtained by previous investigators.

4. On the whole, the data support the methods employed by Lewis and Randall in calculating the activities of mixed electrolytes.

UNIVERSITY, VIRGINIA

[CONTRIBUTION FROM THE DEPARTMENT OF Chemistry OF CORNELI UNiversity]

\section{ABSORPTION OF CARBON DISULFIDE VAPOR BY AQUEOUS SOLUTIONS OF SODIUM TRINITRIDE ${ }^{1}$}

By A. J. Currier with A, W. Browne

Received September 1, 1922

Macagno $^{2}$ has proposed a method for the determination of carbon disulfide which consists in the precipitation of a copper xanthate from the solution obtained by absorption of the disulfide in alcoholic potassium hydroxide. Subsequent measurement of the unused excess of the standard solution of copper sulfate by titration with potassium ferrocyanide yields data from which the amount of carbon disulfide may be computed.

Schmitz-Dumont ${ }^{3}$ considered this method unreliable because under certain conditions the initial reaction between the disulfide and the alkali was not found to be quantitative. He suggested treatment of the alcoholic solution with lead acetate dissolved in $90 \%$ alcohol, resulting in quantitative precipitation of the sulfur as lead sulfide, which is finally oxidized by

1 This article is based upon a part of the thesis submitted by $\mathrm{A}$. J. Currier to the Faculty of the Graduate School of Cornell University in partial fulfilment of the requirements for the degree of Doctor of Philosophy.

2 Macagno, Chem. News, 43, 138 (1881).

${ }^{3}$ Schmitz-Dumont, Chem.-Ztg., 21, 487, 510 (1897), through Chem. Zentr., 1897, II, 265. 